\title{
THE "POSTMODERN TURN" IN THE SOCIAL SCIENCES [Simon Susen, 2015, Basingstoke, Palgrave Macmillan]
}

\author{
Nuno Oliveira \\ Instituto Universitário de Lisboa (ISCTE-IUL), CIES-IUL, Lisboa, Portugal
}

Estaremos a assistir a uma "viragem" pós-moderna nas ciências sociais? Essa parece ser a tese de Simon Susen no seu mais recente livro The "Postmodern Turn" in the Social Sciences. Este livro não é mais uma elaboração crítica sobre a condição pós-moderna nem sobre as contradições do sujeito pós-moderno. Aliás, essa parece ter sido uma voga epocal que se esgotou nos idos anos 90, com múltiplas análises de uma suposta rutura histórica com consequências sociais amplas e determinantes para algo que se poderia caracterizar como um contexto social após a modernidade. Quer dizer, um contexto social em rutura com as estruturas propriamente modernas. Todavia, se atualmente é difícil encontrar alguém nas ciências sociais e humanidades que se autodeclare abertamente como pós-moderno, Susen afirma que a herança deste complexo intelectual perdurou nos modos de pensar e fazer as ciências sociais.

Partindo de uma análise tão extensa quanto criteriosa, Susen pretende mostrar uma mudança epistémica de largo escopo que, segundo ele, invadiu o conhecimento em ciências sociais. O principal argumento do livro, como o autor esclarece, pode ser resumido no seguinte: o postmodern turn nas ciências sociais reflete uma viragem paradigmática da crença iluminista na "determinidade relativa" quer do mundo natural quer do mundo social para a crença pós-iluminista na indeterminação radical de todas as formas simbólicas e materiais de existência (p. 39).

O amplo impacto desta mudança paradigmática manifesta-se em cinco "viragens" pressuposicionais: (a) uma tendência relativista na epistemologia, (b) um enfoque interpretativo na metodologia da investigação social, (c) uma viragem cultural em sociologia, (d) uma mudança contingencial na historiografia, e (e) uma viragem autonomista em política. Cada um destes pontos encerra pressupostos que o autor enuncia e critica de forma axiomática. Ao fazê-lo, oferece uma oportunidade única, pelo desenvolvimento teórico com que o faz, de diagnosticar as interferências do pensamento pós-moderno.

No domínio de uma epistemologia pós-moderna, Susen identifica três grandes oposições cujos contornos metateóricos caracterizam a primeira "viragem". São elas, a tensão objetivismo vs. construtivismo, fundacionalismo vs. antifundacionalismo e universalismo vs. particularismo. Estes pares representam oposições pressuposicionais entre a epistemologia moderna e pós-moderna que possuem impactos em qualquer uma das restantes "viragens".

A mudança interpretativa conhece o seu maior expoente na análise de discurso. Susen salienta que não significa isto que este seja o método mais disseminado em metodologia das ciências sociais, mas que é nele que podemos identificar a influência de três tensões pressuposicionais: entre explicação e compreensão, entre mecânica e dialética e entre ideologia e discurso. Em cada uma destas tensões o que se encontra em causa é uma oposição paradigmática entre abordagens estruturalistas e pós-estruturalistas nas ciências sociais. 
A terceira viragem prende-se com o campo da sociologia. Para Susen assistimos a uma culturalização da sociologia, que remete a materialidade para um segundo plano em relação às trocas simbólicas. Esta culturalização da sociologia surge sobretudo em oposição a posturas teóricas e metodológicas clássicas, nas quais as dimensões económica, material e estrutural se articulavam em relações determinantes do social. Ao invés, a tendência pós-moderna não apenas colocaria em causa a natureza do social - chegando mesmo a negá-lo, como em Baudrillard como as variáveis tradicionais seriam substituídas pelas chamadas soft variables, e o interesse da análise divergiria para o cultural, o simbólico e o representacional. Uma vez mais, no esquema canónico de Susen, uma tal mudança tem subjacentes três tensões: industrialismo vs. pós-industrialismo, produtivismo vs. consumismo, economismo vs. culturalismo.

A respeito da história, Susen sugere que as influências pós-modernas se tornam nítidas no pressuposto da contingência que estas encerram. Em contraste com o projeto moderno de uma história objetiva, com capacidade preditora e dotada de direcionalidade, a historiografia pós-moderna alicerça-se em pressupostos de indeterminação do tempo histórico, inexistência de direcionalidade, formatação discursiva do saber histórico com as suas implicações epistemológicas. As três grandes oposições são, a este propósito, necessidade vs. contingência, grandes narrativas vs. "pequenas" narrativas, continuidade vs. descontinuidade.

Finalmente, a centralidade da autonomia humana no domínio da política. Aqui a mudança das conceções modernas de política para as pós-modernas reside na influência que as políticas de identidade e de reconhecimento têm exercido nas segundas. Desta cabe destacar, no esquema tricotómico prosseguido no livro, a confrontação entre a noção de igualdade com a de diferença, a ideia da sociedade enquanto projeto em contraste com uma multiplicidade de projetos em sociedade e, por último, o reconhecimento da ambivalência contra a univocidade das soluções utópicas.

É inegável que o livro de Susen oferece um levantamento assinalável dos principais debates pós-modernos e das suas reformulações conceptuais (por relação com os instrumentos conceptuais e analíticos da tradição moderna). Adicionalmente, oferece uma crítica tão bem organizada quanto contundente das deficiências do pensamento pós-moderno, e como estas inocularam não somente as ciências sociais como, de forma abrangente, as humanidades. Contudo, julgamos que tem alguns pontos menos conseguidos que merecem discussão. Poder-se-ia dizer que não é tanto a natureza da crítica desenvolvida por Susen, sustentada numa imensa erudição, mas antes a extensão desta crítica que se nos afigura problemática: o facto de esta ser estruturada por um dispositivo retórico que, pese embora a vasteza do conhecimento que patenteia, o poupa a argumentos inovadores.

Mais concretamente quando identifica, por exemplo, o insidioso pós-modernismo na análise de discurso porque esta reivindicaria "um significado sócio-ontológico da contingência espácio-temporal" (p. 238), não creio que essa seja a razão principal pela qual os cientistas sociais fazem análise de discurso. Obviamente, que a questão hermenêutica está presente, assim como está presente na teoria da ação comunicativa, sem que esta reivindique qualquer estatuto pós-moderno. Mas será este o contributo 
da análise de discurso, ou melhor, poder-se-á reduzir a análise de discurso a um intento pós-moderno no sentido da textualização do social? Como caracterizar, por exemplo, as tentativas de compreensão das condições estruturais objetivas de grupos sociais diversos através da análise conversacional, como faz Bourdieu e a sua equipa em La Misère du Monde? Como pensar, nas palavras de Bourdieu no capítulo que justificadamente se intitula "Comprendre", a superação dos instrumentos de pesquisa munidos de categorias apriorísticas e fechadas - como o inquérito por questionário - recorrendo a técnicas conversacionais que visam anular as distâncias e constrangimentos da situação de investigação? Não haverá alguma pertinência metodológica, para além da "nociva" influência pós-moderna, em tais opções? Nem toda a análise de discurso comparte do radicalismo do linguistic turn, em formulações para as quais toda a realidade é texto (Marcus e Fischer, 1986; Geertz, 1973).

Da amplitude de temáticas abordadas por Susen, os impactos na sociologia afiguram-se os mais interessantes para trazer à colação neste texto. Segundo Susen, "uma mudança de formas modernas para pós-modernas de análise" nega o âmago da empresa sociológica, "a sua preocupação com a constituição do social", cujas conceções atuais são afetadas por um cultural turn em sociologia (p. 83). A este propósito, Susen reage a dois desenvolvimentos que ele classifica como participando do mesmo impulso pós-moderno. Por um lado, rejeita as teses latourianas da "morte do social" (Latour, 1991), reafirmando a necessidade de pensar o social enquanto relacionalidade ancorada em processos estruturais. Por outro lado, a constatação de que o que une as três tensões enunciadas anteriormente é o facto de o polo pós-moderno de cada uma ser absorvido pelas interpretações culturais.

Em nossa opinião esta tese deve ser dividida em dois argumentos e estes devem ser interrogados isoladamente. Primeiro, o ataque à constituição do social por parte de correntes pós-estruturalistas, onde se situam a actor network theory (ANT) de Latour e Callon, contra os quais se insurgia Bourdieu (2004: 28) dizendo que não passavam de praticantes de semiologismo, pode ser justificado dentro de uma lógica de crítica à simbolização do social em detrimento da sua constituição estrutural e relacional, da qual o conceito de campo seria o epítome.

Segundo, se existe uma reconsideração do papel da cultura nas relações sociais, não se segue necessariamente que uma especificidade do social seja negada. Seja qual for a relação que estabeleçamos com as teses do pós-industrialismo e da sociedade de consumo - de aberta rejeição ou de acrítica aceitação - , é problemático negar as contribuições que estas têm dado para uma melhor compreensão da realidade social contemporânea. Mesmo que afetemos a uma difusa culturalização da sociologia alguma da inovação conceptual e teórica destas correntes, será por nossa conta e risco que negligenciaremos fenómenos como o crescimento da economia simbólica e dos serviços ou a transição de relações baseadas na produção para relações baseadas no consumo. Veja-se, por exemplo, a crítica que afirma que os processos de industrialização continuam, mas desta feita deslocalizados, como se isso infirmasse a capacidade estruturante da economia simbólica tanto das desigualdades como das localizações. Dito isto, não significa que nos devamos fascinar com a estetização dos processos sociais negligenciando os seus efeitos de 
dominação. Susen está correto quando aponta os perigos de despolitização encobertos pelo pós-modernismo estético (p. 249).

Todavia, podemos pensar que, se a cultura granjeia uma posição privilegiada em muitas destas análises, é porque ela merece em diversas instâncias ser tratada como variável independente com efeitos sobre estruturas e práticas. Da mesma forma, torna-se discutível a oposição entre uma sociologia cultural e uma sociologia da cultura, como Susen pretende insistir, na premissa de que a primeira hipostasiaria o cultural e a segunda explicitaria as suas bases estruturais. Como mostram os trabalhos de Lamont (1992, 1995; Lamont, Beljean e Clair, 2014), estes corpos teóricos podem estabelecer relações de complementaridade, em particular no que diz respeito à articulação entre o simbólico e o social quando esta é perspetivada em termos não reducionistas. Por exemplo, na compreensão da utilização de recursos simbólicos (distinções conceptuais, estratégias interpretativas, tradições culturais) na criação, manutenção, contestação ou mesmo dissolução de diferenças sociais institucionalizadas (classe, género, "raça", desigualdade territorial).

Na conclusão, Susen contesta a extensão da mudança anunciada pelo pensamento pós-moderno. Nas suas palavras, "as ideias basilares e instituições da sociedade moderna continuam a existir na época contemporânea: as ideias centrais de estado-nação, família nuclear, conflito de classes, relações internacionais, estado-providência, democracia e conhecimento científico" (p. 239). ${ }^{1}$ Podemos a justo título perguntar o que Susen acrescenta a noções tais como modernidade tardia (Giddens, 1991) ou modernidade líquida (Bauman, 2000). O que torna o capítulo, no mínimo, estranho na medida em que discute as inconsistências do pensamento pós-moderno enquanto articulado em torno do sufixo "pós", como se ninguém tivesse proposto a tese oposta de uma extensão (e intensificação) das forças e formas sociais típicas da modernidade. Assim, ao afirmar de maneira incisiva que a modernidade é um projeto autorreflexivo, é difícil não pensar de imediato nas formas reflexivas de autoidentidade como projetos reflexivos modernos e intensificados na modernidade tardia assim como teorizadas por Giddens.

Por conseguinte, ficamos com uma crítica exaustiva, por vezes demolidora, do panorama atual das ciências sociais, mas que nos deixa, infelizmente, em caminhos para lado nenhum. Mesmo que quiséssemos concordar com o autor na necessidade de um regresso ao universalismo, fundacionalismo e racionalismo do projeto iluminista não podemos deixar de nos interrogar sobre a forma de integrar tais pressupostos num novo paradigma para as ciências sociais e humanidades. Por certo, nem todos os livros apresentam teses originais. Porém, quando o objetivo é desconstruir toda produção intelectual que pressupõe, para o autor, vieses pós-modernos, então seria expectável apresentar o seu próprio modelo de ciência social.

Em síntese, apesar de pródiga em questionamentos, mas parca em soluções, dificilmente se encontrará uma análise tão rigorosa quanto abrangente

1 Tradução do autor: "basic ideals and institutions of modern society continue to exist in the contemporary age: 'the core ideas of the nation-state, the nuclear family, class conflict, international relations, the welfare state, nation-state democracy and scientific knowledge" (p. 239). 
dos impactos do pensamento pós-moderno nas ciências sociais como a que é oferecida por Susen nesta obra.

\section{Referências bibliográficas}

Bauman, Z. (2000), Liquid Modernity, Cambridge, Polity Press.

Bourdieu, P. (1999), The Weight of the World, Cambridge, Polity Press.

Bourdieu, P. (2004), Science of Science and Reflexifity, Chicago, The University of Chicago Press.

Geertz, C. (1973) "Thick description: toward an interpretative theory of culture", em C. Geertz, The Interpretation of Cultures, Nova Iorque, Basic Books, pp. 3-30.

Giddens, A. (1990), The Consequences of Modernity, Cambridge, Polity Press.

Giddens, A. (1991), Modernity and Self-Identity. Self and Society in the Late Modern Age, Cambridge, Polity Press.

Lamont, M. (1992), Money, Morals \& Manners. The Culture of the French and American Upper-Middle Class, Chicago, The University of Chicago Press.

Lamont, M. (1995), The Dignity of Working Men. Morality and the Boundaries of Race, Class and Citizenship, Cambridge, MA, Harvard University Press; Nova Iorque, Russell Sage Foundation.

Lamont, M., S. Beljean, e M. Clair (2014), “What is missing? Cultural processes and causal pathways to inequality", Socio-Economic Review, 12, pp. 573-608.

Latour, Bruno (1991), Nous n'Avons Jamais Eté Modernes. Essai d'Anthropologie Symétrique, Paris, La Découverte, Poche / Sciences humaines et sociales.

Marcus, G. E., e M. M. J. Fischer (1986), Anthropology as Cultural Critique. An Experimental Moment in the Human Sciences, Chicago, The University of Chicago Press.

Nuno Oliveira. Pós-doutorando no Instituto Universitário de Lisboa (ISCTE-IUL), Centro de Investigação e Estudos de Sociologia (CIES-IUL), Lisboa, Portugal. E-mail: filicastrol@gmail.com 